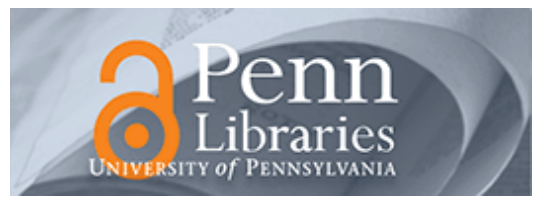

University of Pennsylvania

ScholarlyCommons

Finance Papers

Wharton Faculty Research

2008

\title{
Asset Prices Under Habit Formation and Reference-Dependent Preferences
}

Motohiro Yogo

University of Pennsylvania

Follow this and additional works at: https://repository.upenn.edu/fnce_papers

Part of the Finance Commons, and the Finance and Financial Management Commons

\section{Recommended Citation}

Yogo, M. (2008). Asset Prices Under Habit Formation and Reference-Dependent Preferences. Journal of Business \& Economic Statistics, 26 (2), 131-143. http://dx.doi.org/10.1198/073500107000000205

This paper is posted at ScholarlyCommons. https://repository.upenn.edu/fnce_papers/316

For more information, please contact repository@pobox.upenn.edu. 


\title{
Asset Prices Under Habit Formation and Reference-Dependent Preferences
}

\author{
Abstract \\ This article explains the high level and the countercyclical variation of the equity premium in a \\ consumption-based asset pricing model with low large-scale risk aversion. Investors have gain-loss utility \\ over consumption relative to slowly time-varying habit. Stocks deliver low returns in recessions when \\ consumption falls below habit; investors therefore require a high premium for holding stocks. The model's \\ conditional moment restrictions are tested on consumption and asset returns data. The empirical \\ estimate of large-scale risk aversion is low, whereas the estimate of loss aversion agrees with prior \\ experimental evidence. \\ Disciplines \\ Finance | Finance and Financial Management
}


Asset Prices Under Habit Formation and Reference-Dependent Preferences

Motohiro Yogo

08-07 


\title{
Asset Prices Under Habit Formation and Reference-Dependent Preferences
}

\author{
Motohiro Yogo*
}

\begin{abstract}
This article explains the high level and the countercyclical variation of the equity premium in a consumption-based asset pricing model with low large-scale risk aversion. Investors have gain-loss utility over consumption relative to slowly time-varying habit. Stocks deliver low returns in recessions when consumption falls below habit; investors therefore require a high premium for holding stocks. The model's conditional moment restrictions are tested on consumption and asset returns data. The empirical estimate of large-scale risk aversion is low, whereas the estimate of loss aversion agrees with prior experimental evidence.
\end{abstract}

KEY WORDS: Asset pricing; Consumption; Equity premium; Habit formation; Loss aversion.

\footnotetext{
${ }^{*}$ The Wharton School, University of Pennsylvania, Philadelphia, PA 19104 and the National Bureau of Economic Research, Cambridge, MA 02138 (yogo@wharton.upenn.edu)
} 



\section{INTRODUCTION}

The consumption-based asset pricing model (CCAPM) with power utility fails to explain important facts about stock returns, including the high equity premium, the high volatility of returns, and the countercyclical variation in the equity premium. (See Grossman and Shiller 1981; Shiller 1982; Mehra and Prescott 1985; Kandel and Stambaugh 1990) In response to these failures, financial economists have considered alternative models of preferences. One prominent approach is habit formation, in which utility depends on consumption relative to a reference level of consumption. (See Sundaresan 1989; Abel 1990; Constantinides 1990; Ferson and Constantinides 1991; Campbell and Cochrane 1999) Although habit-based asset pricing models are able to quantitatively match the key empirical facts, these models must ultimately appeal to high risk aversion to explain the high equity premium (Campbell and Cochrane 1999, p. 243). A problem with high risk aversion is that it has unappealing implications for large-scale risk (Kandel and Stambaugh 1991; Rabin 2000).

This article proposes a habit-based asset pricing model with low large-scale risk aversion that explains the key empirical facts, namely the low real interest rate, the high equity premium, and the countercyclical variation in the equity premium. The model is a standard identical-agent economy with external habit formation (e.g., Abel 1990; Campbell and Cochrane 1999). The point of departure from previous work is a new utility function for evaluating "gains and losses" in consumption relative to habit. Specifically, I embed habit formation in the reference-dependent model of Köszegi and Rabin (2006), which ties together neoclassical consumption utility with the gain-loss utility of Kahneman and Tversky (1979). The model offers a parsimonious framework to think about both large-scale risk aversion and loss aversion. Risk aversion refers to the curvature of consumption utility, which determines the household's behavior for large gambles. Loss aversion refers to the magnitude of marginal utility for losses relative to gains, which determines the household's behavior for small gambles.

Previous work, notably Benartzi and Thaler (1995) and Barberis, Huang, and Santos 
(2001), has shown that loss aversion can explain asset pricing puzzles. A key feature of these models is that households care about gains and losses in financial (rather than total) wealth, which is partly motivated by narrow framing (Barberis and Huang 2007). In this article, households care about gains and losses in consumption. One can debate which of the two approaches model household preferences in a more realistic way, but more importantly, the two models offer different answers to the key economic questions. Do small (relative to stock returns) fluctuations in consumption affect household utility in a significant way? And why is the equity premium so high? In Barberis, Huang, and Santos (2001), households have power utility with low risk aversion, so small fluctuations in consumption do not significantly affect utility. The high equity premium is explained by the fact that investors care about fluctuations in financial wealth, which capture "feelings unrelated to consumption" (p. 6). This article offers an alternative view that households are averse to losses in consumption relative to habit, so that even small fluctuations in consumption affect utility. The high equity premium is the reward that investors require for holding stocks, which deliver low returns during recessions when consumption approaches or falls below habit.

The asset pricing model in this article is closely related to models based on the theory of disappointment aversion (Gul 1991). Disappointment aversion generates a high equity premium and a low risk-free rate (Epstein and Zin 1990, 2001; Bonomo and Garcia 1994) as well as time-varying risk premia (Bekaert, Hodrick, and Marshall 1997). The key economic mechanism is first-order risk aversion, which gives rise to risk premia that are proportional to the standard deviation (rather than the variance) of consumption growth. Relative to this literature, the model in this article has two distinct features. First, the reference level is habit, which is a geometric average of past consumption. In disappointment aversion, the reference level is the certainty equivalent of future utility. Second, preferences based on loss aversion have the advantage of experimental evidence from psychology, which gives rise to explicit guidance for calibration and estimation.

The rest of the article is organized as follows. Section 2 introduces a general class of 
reference-dependent preferences based on the work of Kőszegi and Rabin (2006). A methodological contribution of this section is to link together previously proposed functional forms of reference dependence in a unifying framework. Both the ratio model (i.e., Abel 1990) and the difference model (i.e., Constantinides 1990) are derived from standard gain-loss functions.

Section 3 derives equilibrium asset returns for a lognormal endowment economy under habit formation and reference-dependent preferences. Whereas the formal test of the reference-dependent model is through estimation, rather than calibration, the calculations in this section provide insights into the relative contributions of loss aversion and habit formation in explaining asset prices. Loss aversion is important for explaining the level of the equity premium, whereas habit formation is important for explaining the time variation in the equity premium. Although the risk-free rate is more volatile than it is in the power utility model, persistence in the habit process within the reference-dependent framework can mitigate excessive volatility of the risk-free rate.

Section 4 estimates and tests the reference-dependent model through its conditional moment restrictions. The empirical estimate of risk aversion is consistent with what economists believe are reasonable predictions for large gambles, based on the thought experiments of Kandel and Stambaugh (1991). The empirical estimate of loss aversion is consistent with prior experimental evidence (Tversky and Kahneman 1992). The model successfully fits a set of time series moments implied by the T-bill rate, the market return, and instruments that predict returns. However, the model fails on a set of cross-sectional moments implied by portfolios sorted by size and book-to-market equity.

Section 5 concludes. The appendixes contain descriptions of the data and derivations omitted in the main text. 


\section{A GENERAL CLASS OF REFERENCE-DEPENDENT PREFERENCES}

Let $W(z)$ be a gain-loss function (Kahneman and Tversky 1979), which has the following properties:

1. $W(z)$ is continuous and strictly increasing for all $z \in \mathbb{R}$, where $W(0)=0$.

2. $W(z)$ is twice differentiable for all $z \neq 0, W^{\prime \prime}(z) \leq 0$ for all $z>0$, and $W^{\prime \prime}(z) \geq 0$ for all $z<0$.

3. $W(y)+W(-y)<W(z)+W(-z)$ for all $y>z>0$, and $\lim _{z \downarrow 0} W^{\prime}(-z) / W^{\prime}(z)=\lambda>1$.

Property 1 is monotonicity, that utility is strictly increasing in the magnitude of gain. Property 2 is diminishing sensitivity, that the marginal effect of a gain or a loss diminishes with its magnitude. Property 3 is loss aversion, that the impact of a loss is greater than that of an equally sized gain. That the impact of an arbitrarily small loss is greater than that of an arbitrarily small gain gives rise to a kink in the gain-loss function at $z=0$ (Bowman, Minehart, and Rabin 1999).

Let $v(C)$ be a neoclassical utility function that is continuously differentiable, strictly increasing, and concave for all $C>0$. Following Köszegi and Rabin (2006), consider a general class of reference-dependent preferences given by

$$
u(C, X)=\alpha v(C)+(1-\alpha) W(v(C)-v(X)),
$$

where $\alpha \in[0,1]$. Reference-dependent utility (1) is a weighted sum of two parts. The first part $v(C)$ is consumption utility, that is, neoclassical utility derived from consumption $C$. The second part $W(v(C)-v(X))$ is gain-loss utility, that is, utility derived from the deviation of consumption utility $v(C)$ from its reference level $v(X)$. The variable $X$ denotes the reference level of consumption. The household derives positive (negative) gain-loss utility when $C$ 
exceeds (is exceeded by) $X$. Preferences that depend on a reference level of consumption have psychological foundations in hedonic adaptation (see Frederick and Loewenstein 1999).

Let subscripts denote partial derivatives. Marginal utility with respect to consumption and its reference level are given by

$$
\begin{aligned}
& u_{C}=v^{\prime}(C)\left[\alpha+(1-\alpha) W^{\prime}(v(C)-v(X))\right]>0, \\
& u_{X}=-(1-\alpha) v^{\prime}(X) W^{\prime}(v(C)-v(X)) \leq 0,
\end{aligned}
$$

whenever $C \neq X$. In words, utility is strictly increasing in consumption and decreasing in the reference level. Marginal utility is not well defined at $C=X$ due to the kink in the gain-loss function arising from loss aversion.

Suppose the gain-loss function satisfies a slightly stronger version of diminishing sensitivity (Property 2):

2'. $W(z)$ is twice differentiable for all $z \neq 0, W^{\prime \prime}(z)<0$ for all $z>0, W^{\prime \prime}(z)>0$ for all $z<0$, and $\lim _{z \rightarrow \pm \infty} W^{\prime}(z)=0$.

Then $\lim _{C-X \rightarrow \pm \infty} u_{C}=\alpha v^{\prime}(C)$. That is, for large deviations in consumption from the reference level, the behavior of the household is the same as that with neoclassical consumption utility. This large-risk behavior of reference-dependent utility agrees with the common view that neoclassical utility is adequate for describing aversion to large risks, but not to small risks (see Rabin 2000).

For the rest of the article, I make three parametric assumptions regarding referencedependent utility (1). First, I assume that the household has only gain-loss utility (i.e., $\alpha=$ 0 ). In consumption-based asset pricing models, identification of the preference parameters occurs in the domain of small gambles because the volatility of aggregate consumption is low (Kandel and Stambaugh 1991). For small gambles, gain-loss utility is much more important than direct consumption utility, implying that the observed household behavior is similar for all $\alpha<1$. (In econometric language, the parameter is nearly unidentified in the region 
$\alpha<1$.) Second, I assume that the household has power utility

$$
v(C)=\frac{C^{1-\gamma}}{1-\gamma} \quad(\gamma \geq 0),
$$

where the special case $\gamma=1$ is understood to be $\log$ utility $v(C)=\log C$. Third, I assume that the household has power gain-loss utility.

\subsection{Power Gain-Loss Utility}

The power gain-loss function (Tversky and Kahneman 1992) is specified as

$$
W_{P}(z)=\left\{\begin{array}{cc}
\frac{z^{1-\theta}}{1-\theta} & \text { for } z \geq 0 \\
-\lambda \frac{|z|^{1-\theta}}{1-\theta} & \text { for } z<0
\end{array} \quad(\theta \in[0,1), \lambda>1)\right.
$$

The parameter $\theta$ determines the degree of diminishing sensitivity, and the parameter $\lambda$ determines the degree of loss aversion. Using experimental data, Tversky and Kahneman (1992) obtained the parameter estimates $\theta=0.12$ and $\lambda=2.25$. When $\theta>0$, the power

gain-loss function satisfies the strong version of diminishing sensitivity (Property $2^{\prime}$ ). The special case $\theta=0$ corresponds to the linear gain-loss function

$$
W_{L}(z)=\left\{\begin{array}{cc}
z & \text { for } z \geq 0 \\
\lambda z & \text { for } z<0
\end{array} \quad(\lambda>1)\right.
$$

Power reference-dependent utility is defined as a special case of reference-dependent utility with power consumption utility (2) and power gain-loss utility (3). The marginal utility of consumption in this case is

$$
u_{C}=\left\{\begin{array}{ll}
C^{-\gamma}\left(\frac{C^{1-\gamma}}{1-\gamma}-\frac{X^{1-\gamma}}{1-\gamma}\right)^{-\theta} & \text { for } C>X \\
\lambda C^{-\gamma}\left|\frac{C^{1-\gamma}}{1-\gamma}-\frac{X^{1-\gamma}}{1-\gamma}\right|^{-\theta} & \text { for } C<X
\end{array} .\right.
$$


The marginal utility of consumption when $C<X$ is higher than that when $C>X$ by a factor $\lambda$. The higher is the degree of loss aversion, the higher is the difference in marginal utility between these two states of the world.

To motivate power reference-dependent utility, consider the special case when consumption utility takes the linear utility form (i.e., $\gamma=0$ ). Household utility simplifies to yield the difference specification

$$
u(C, X)=\left\{\begin{array}{ll}
\frac{(C-X)^{1-\theta}}{1-\theta} & \text { for } C \geq X \\
\lambda \frac{|C-X|^{1-\theta}}{1-\theta} & \text { for } C<X
\end{array} .\right.
$$

Utility function (6) differs from the usual specification of the difference model (i.e., Constantinides 1990) in two important ways. First, the parameter $\theta \in[0,1)$ has the interpretation of diminishing sensitivity, rather than risk aversion. Second, utility is well defined even when consumption falls below its reference level. The modeling convention that consumption never falls below its reference level can be thought of as optimal behavior for a household that is highly loss averse (i.e., $\lambda \gg 1)$. Appendix A shows that the ratio model (i.e., Abel 1990) can also be obtained as a special case of reference-dependent utility (1) when the gain-loss function is exponential.

\subsection{Implications of Reference-Dependent Utility for Small and Large Gambles}

Table 1 replicates a simple thought experiment in Kandel and Stambaugh (1991). Suppose a household has initial wealth $\$ 75,000$. In Panel A, the household faces a "small" gamble of $\pm \$ 375$ ( $0.5 \%$ of wealth) with equal probability. In Panel B, the household faces a "large" gamble of $\pm \$ 25,000$ (33\% of wealth) with equal probability. The table reports the amount of a sure loss in wealth that makes the household indifferent to facing the gamble. Equivalently, the household is willing to pay the amount reported in the table to avoid the gamble. 
Power utility, used in the canonical CCAPM, has difficulty explaining the household's behavior for both small and large gambles. When $\gamma=30$, the household is willing to pay $\$ 28.03$ to avoid the small gamble, and $\$ 23,791$ to avoid the large gamble. The amount that the household is willing to pay to avoid the large gamble seems implausibly large. When $\gamma=2$, the household is willing to pay $\$ 1.88$ to avoid the small gamble, and $\$ 8,333$ to avoid the large gamble. The amount that the household is willing to pay to avoid the large gamble is more reasonable, but the amount paid to avoid the small gamble seems implausibly small. This tension between small- and large-risk behavior arises from the fact that any concave utility function implies approximate risk neutrality for sufficiently small gambles (Rabin 2000).

I now conduct the same thought experiment for reference-dependent utility at varying degrees of diminishing sensitivity $\theta=\{0,0.12\}$ and risk aversion $\gamma \in[0,30]$. I fix the degree of loss aversion at $\lambda=2.25$, and the reference level of consumption at $X=\$ 75,000$. In contrast to power utility, reference-dependent utility is able to explain the household's behavior for both small and large gambles with the same set of preference parameters. For example, when $\theta=0.12$ and $\gamma=1$, the household is willing to pay $\$ 87.99$ to avoid the small gamble, and $\$ 8,301$ to avoid the large gamble. In general, the willingness to pay decreases in $\theta$ due to the convexity of gain-loss utility for losses, and increases in $\gamma$ due to the concavity of consumption utility.

For small gambles in Panel A, the household's willingness to pay does not vary much in $\gamma$. In other words, gain-loss utility (parameterized by $\theta$ and $\lambda$ ) plays a more prominent role in explaining the household's behavior for small gambles. For large gambles in Panel B, the household's willingness to pay varies significantly in $\gamma$. In other words, consumption utility (parameterized by $\gamma$ ) plays a more prominent role in describing the household's behavior for large gambles. For this reason, I will refer to the parameter $\gamma$ as large-scale risk aversion, to give it a name that is appropriate for its economic role. When $\gamma \geq 10$, the amount that the household is willing to pay to avoid the large gamble is implausibly large. 
The fact that observed behavior does not vary much in $\gamma$ for small gambles presents a problem for the identification of the parameter. In experimental studies, test subjects can only be subject to small gambles for ethical reasons. Therefore, measurements of $\gamma$ will be confounded by the effect of loss aversion, which dominates behavior in the domain of small gambles. In estimating preference parameters from macroeconomic data, Kandel and Stambaugh (1991) emphasized that identification occurs in the domain of small gambles because aggregate consumption has low volatility. This is not to say that macroeconomic risks faced by households are small, but rather that observed consumption is an equilibrium outcome of an optimizing household that smooths consumption in the presence of risk. It is therefore important to have a model that accurately describes household behavior not only for large gambles, but also for small gambles.

\section{ASSET PRICES UNDER REFERENCE-DEPENDENT PREFERENCES}

\subsection{An Economy with External Habit Formation}

To study the asset pricing implications of reference-dependent preferences, I consider a simple endowment economy with external habit formation, following Abel (1990) and Campbell and Cochrane (1999). The economy is composed of identical households, indexed by $h$, that maximize the expected discounted sum of future utility flows

$$
\mathbf{E}_{0} \sum_{t=0}^{\infty} \beta^{t} u\left(C_{h t}, X_{t}\right) .
$$

The parameter $\beta>0$ is the household's subjective discount factor, and $C_{h t}$ is its consumption in period $t$.

Each household's utility depends on a common reference level of consumption, referred to as external habit $X_{t}$. External habit has an economic interpretation as the "subsistence 
level" or "standard of living." Specifically, external habit has the dynamics

$$
X_{t+1}=\exp \{\delta\} X_{t}^{\phi} C_{t}^{1-\phi}
$$

where $C_{t}$ is per capita consumption in period $t$ and $\phi \in[0,1)$. Habit is a geometric average of past consumption, rather than an arithmetic average as in Constantinides (1990). The model of habit in Ferson and Constantinides (1991) is a special case where $\phi=0$.

Let $G_{t+1}=C_{t+1} / C_{t}$ denote consumption growth, and let $Y_{t}=C_{t} / X_{t}$ denote the consumptionhabit ratio. Also let lowercase letters denote the log of the corresponding uppercase variables. Then the log consumption-habit ratio can be expressed as

$$
y_{t+1}=-\delta+\phi y_{t}+g_{t+1}
$$

In words, the consumption-habit ratio is an $\mathrm{AR}(1)$ with consumption growth as its innovation. Consumption and habit are cointegrated in this model, with the parameter $\phi$ capturing the degree of persistence in the deviation of consumption from habit. Model (9) is simpler than the model of habit in Campbell and Cochrane (1999), but has the same economic mechanisms. Additional complications are unnecessary because the reference-dependent preferences in this article are well defined even when consumption falls below habit (i.e., $\left.y_{t}<0\right)$.

Because households in this economy are identical, $C_{h t}=C_{t}$ in equilibrium. I will therefore drop the subscript $h$ to simplify notation. Under power reference-dependent utility (5), the intertemporal marginal rate of substitution (IMRS) takes the form

$$
M_{t+1}=\beta G_{t+1}^{-\gamma} \frac{w\left(Y_{t+1}\right)}{w\left(Y_{t}\right)}
$$


where

$$
w\left(Y_{t}\right)=\left\{\begin{array}{ll}
\left(\frac{C_{t}^{1-\gamma}}{1-\gamma}-\frac{X_{t}^{1-\gamma}}{1-\gamma}\right)^{-\theta} & \text { for } Y_{t}>1 \\
\lambda\left|\frac{C_{t}^{1-\gamma}}{1-\gamma}-\frac{X_{t}^{1-\gamma}}{1-\gamma}\right|^{-\theta} & \text { for } Y_{t}<1
\end{array} .\right.
$$

Under linear reference-dependent utility, which is the special case $\theta=0$, this simplifies to

$$
w_{L}\left(Y_{t}\right)=\left\{\begin{array}{cc}
1 & \text { for } Y_{t}>1 \\
\lambda & \text { for } Y_{t}<1
\end{array} .\right.
$$

Let $R_{i, t+1}$ be the gross return on an asset $i$ from period $t$ to $t+1$. The household's first-order conditions and the envelope theorem imply the Euler equation

$$
\mathbf{E}_{t}\left[M_{t+1} R_{i, t+1}\right]=1
$$

Because of convexity in the domain of losses $Y_{t}<1,(13)$ is necessary, but not sufficient, for an interior optimum. An interior optimum is guaranteed if the curvature of power utility is large relative to the degree of diminishing sensitivity. More precisely, the sufficient condition is satisfied if $\gamma>\theta /\left|1-Y_{t}^{\gamma-1}\right|$ for $Y_{t}<1$, which is trivially satisfied for the linear gain-loss function (i.e., $\theta=0$ ).

The rest of Section 3 focuses on the asset pricing implications of the Euler equation for linear reference-dependent utility (12). I focus on this special case because I can calculate closed-form expressions for asset returns, which provide basic intuition for the effects of loss aversion and habit formation on asset prices. In Section 4, I estimate the Euler equation for the general case based on power reference-dependent utility (11).

\subsection{Asset Prices in a Lognormal Endowment Economy}

Suppose households have linear reference-dependent utility, and consumption is conditionally

lognormal. That is, $g_{t+1} \sim \mathbf{N}\left(\mu_{t}, \sigma_{t}^{2}\right)$, where I drop the subscript $t$ in the moments of 
consumption growth to simplify notation. Then equilibrium asset returns, specifically the risk-free rate and the maximum Sharpe ratio, can be calculated explicitly as functions of the preference parameters and the moments of consumption growth.

\subsubsection{Risk-Free Rate}

Let $R_{f t}$ be the gross return on a conditionally risk-free asset in period $t$, and let $F(z)=$ $\operatorname{Pr}(Z<z)$ denote the cumulative distribution function of a standard normal random variable $Z$. The following proposition is proved in Appendix B.

Proposition 1. Suppose $g_{t+1} \sim \mathbf{N}\left(\mu, \sigma^{2}\right)$, and the IMRS is given by (10) and (12). Then a conditionally risk-free asset has the return

$$
R_{f, t+1}=\left[\beta \exp \left\{-\gamma \mu+\frac{\gamma^{2} \sigma^{2}}{2}\right\} A_{t}(\gamma, \lambda)\right]^{-1}
$$

where

$$
A_{t}(\gamma, \lambda)=\left\{\begin{array}{cc}
1+(\lambda-1) F\left(\gamma \sigma+\frac{\delta-\mu-\phi y_{t}}{\sigma}\right) & \text { for } y_{t}>0 \\
1 / \lambda+(1-1 / \lambda) F\left(\gamma \sigma+\frac{\delta-\mu-\phi y_{t}}{\sigma}\right) & \text { for } y_{t}<0
\end{array}\right.
$$

The function $A_{t}(\gamma, \lambda)$ has the following properties:

1. $\partial A_{t}(\gamma, \lambda) / \partial \lambda \gtrless 0$ if $y_{t} \gtrless 0$.

2. $\partial A_{t}(\gamma, \lambda) / \partial y_{t}<0$ if $\phi>0$.

When $\lambda=1$, which corresponds to the power utility model, $A_{t}(\gamma, 1)=1$. The risk-free rate then simplifies to the familiar expression

$$
R_{f, t+1}=\beta^{-1} \exp \left\{\gamma \mu-\frac{\gamma^{2} \sigma^{2}}{2}\right\}
$$

The first term inside the exponential function represents intertemporal substitution, and the 
second term represents precautionary savings. The higher is risk aversion $\gamma$, the stronger is the intertemporal motive to borrow, and the stronger is the precautionary motive to save.

To understand how loss aversion affects the risk-free rate, it is helpful to first consider the special case $\phi=0$. Define a "boom" as a period in which consumption exceeds habit (i.e., $y_{t}>0$ ), and a "recession" as a period in which consumption is exceeded by habit (i.e., $y_{t}<0$ ). (Both the mean and variance of consumption growth are assumed to be constant in the discussion that follows.) Compared to the constant level in the power utility benchmark, the risk-free rate (14) is lower in a boom and higher in a recession. Intuitively, marginal utility is low in a boom, so the household is motivated to save the marginal dollar for the possibility of a recession tomorrow, driving down the equilibrium interest rate. On the other hand, marginal utility is high in a recession, so the household is motivated to borrow, driving up the equilibrium interest rate. This "precautionary motive" induced by loss aversion is proportional to $\sigma$ [because $F(\gamma \sigma+(\delta-\mu) / \sigma)$ is of order $\sigma$ ]. This is in contrast to the precautionary motive induced by risk aversion, which is proportional to $\sigma^{2}$. In that sense, linear reference-dependent utility exhibits first-order risk aversion (Segal and Spivak 1990).

For a sufficiently high degree of loss aversion, the risk-free rate can be excessively countercyclical in the special case $\phi=0$. This is where persistence in habit, parameterized as $\phi>0$, plays a key economic role in inducing the right amount of precautionary motive to save. Intuitively, marginal utility is low in a boom, but the household is unmotivated to save the marginal dollar because consumption is expected to remain high relative to habit tomorrow. Conversely, marginal utility is high in a recession, but the household is unmotivated to borrow because consumption is expected to remain low relative to habit tomorrow. On the one hand, persistence in habit reduces the volatility of the risk-free rate that arises from movements in the consumption-habit ratio across the two regimes, $y_{t}>0$ and $y_{t}<0$. On the other hand, persistence in habit increases the volatility of the risk-free rate within each regime. If the former is a relatively strong source of volatility, persistence in habit can help lower the overall volatility of the risk-free rate. 


\subsubsection{Maximum Sharpe Ratio}

Let $R_{e t}=R_{i t}-R_{j t}(i \neq j)$ be a generic excess return in period $t$. The following proposition is proved in Appendix B.

Proposition 2. Suppose $g_{t+1} \sim \mathbf{N}\left(\mu, \sigma^{2}\right)$, and the IMRS is given by (10) and (12). Then the Sharpe ratio for any excess return has the bound

$$
\frac{\mathbf{E}_{t}\left[R_{e, t+1}\right]}{\sigma_{t}\left(R_{e, t+1}\right)} \leq\left[\exp \left\{\gamma^{2} \sigma^{2}\right\} B_{t}(\gamma, \lambda)-1\right]^{1 / 2}
$$

where

$$
B_{t}(\gamma, \lambda)=\frac{1+\left(\lambda^{2}-1\right) F\left(2 \gamma \sigma+\left(\delta-\mu-\phi y_{t}\right) / \sigma\right)}{\left[1+(\lambda-1) F\left(\gamma \sigma+\left(\delta-\mu-\phi y_{t}\right) / \sigma\right)\right]^{2}}
$$

The function $B_{t}(\gamma, \lambda)$ has the following properties:

1. $B_{t}(\gamma, \lambda) \geq 1$ and $\partial B_{t}(\gamma, \lambda) / \partial \lambda>0$.

2. $\partial B_{t}(0, \lambda) / \partial y_{t}<0$ if $\phi>0$ and

$$
y_{t}>\frac{\sigma}{\phi}\left[\frac{\delta-\mu}{\sigma}-F^{-1}\left(\frac{1}{\lambda+1}\right)\right] \text {. }
$$

When $\lambda=1$, which corresponds to the power utility model, $B_{t}(\gamma, 1)=1$. The maximum Sharpe ratio then simplifies to the familiar expression

$$
\frac{\mathbf{E}_{t}\left[R_{e, t+1}\right]}{\sigma_{t}\left(R_{e, t+1}\right)} \leq\left[\exp \left\{\gamma^{2} \sigma^{2}\right\}-1\right]^{1 / 2} \approx \gamma \sigma
$$

The higher is risk aversion $\gamma$, the higher is the premium for holding risky assets.

Compared to the level in the power utility benchmark, the maximum Sharpe ratio (17) is strictly greater and monotonically increasing in $\lambda$. Simply put, the higher is the degree of loss aversion, the greater is the reward that households demand for bearing risk. Due to loss 
aversion, the Sharpe ratio is proportional to $\sqrt{\sigma}$ [because $F(2 \gamma \sigma+(\delta-\mu) / \sigma)$ is of order $\sigma$ ]. This is in contrast to the Sharpe ratio based on risk aversion alone, which is proportional to $\sigma$. In that sense, linear reference-dependent utility exhibits first-order risk aversion, which can explain the high historical equity premium (Epstein and Zin 1990).

When $\phi>0$, the consumption-habit ratio $y_{t}$ is a state variable that induces time variation in the maximum Sharpe ratio. For the special case $\gamma=0$, Proposition 2 states that the Sharpe ratio falls in the consumption-habit ratio at sufficiently high levels of $y_{t}$. Intuitively, the IMRS is most volatile, and consequently, the Sharpe ratio is highest near the kink in the utility function (i.e., $y_{t} \approx 0$ ). For the Sharpe ratio to be countercyclical, consumption must stay well above habit in booms and come close to (or fall slightly below) habit only in recessions. Section 4 estimates the dynamics of habit and verifies that it has this empirical property.

Barberis, Huang, and Santos (2001) raised an important critique of habit-based asset pricing models. Because movements in expected returns are ultimately driven by consumption, consumption growth and stock returns are highly correlated. To the extent that the empirical correlation between consumption growth and stock returns is low, this prediction is a failure of this class of models. However, the correlation between consumption growth and returns is notoriously difficult to measure, so the low correlation may not be a robust feature of the data that all models must match. For example, Parker (2001) found significantly higher correlation between consumption growth and stock returns when measured over longer horizons.

\subsection{Equity Premium Puzzle}

Table 2 reports descriptive statistics for consumption and asset returns in the quarterly sample 1947-2004. (See Appendix C for a complete description of the data.) Log real consumption growth has mean $0.50 \%$ and standard deviation $0.54 \%$. The real (ex post) T-bill rate has mean $0.36 \%$ and standard deviation $0.75 \%$. The table reports descriptive 
statistics for real excess returns on three portfolios: the value-weighted market portfolio, the SMB (Small Minus Big stock) portfolio, and the HML (High Minus Low book-to-market) portfolio. The equity, size, and value premia in this sample are $1.99 \%, 0.61 \%$, and $1.04 \%$, respectively. As is well known, the high Sharpe ratio of 0.25 for excess stock returns is difficult to reconcile with the low volatility of consumption growth in standard asset pricing models (Mehra and Prescott 1985).

To illustrate this well-known failure, suppose log consumption growth is normal with $\mu=0.50 \%$ and $\sigma=0.54 \%$. Assume that households have power utility with $\beta=0.99$ and $\gamma=1$. Then the risk-free rate implied by (16) is $1.51 \%$, which is somewhat higher but comparable to the historical mean of the T-bill rate. However, the Sharpe ratio implied by (20) is merely 0.005 , which is two orders of magnitude lower than the historical Sharpe ratio for equity 0.25. A higher risk aversion of $\gamma=20$ raises the Sharpe ratio to 0.11, but at the cost of raising the risk-free rate to $10.98 \%$. Therefore, a "resolution" of the equity premium puzzle through higher risk aversion results in a risk-free rate puzzle (Weil 1989). Aside from this problem, high risk aversion in itself is problematic because of its implications for large-scale risk (as shown in Table 1).

Now consider linear reference-dependent utility with the parameters $\beta=0.99, \gamma=1$, and $\lambda=2.25$. Assume for now that $\delta=\phi=0$, so that habit has the simple dynamics $X_{t+1}=C_{t}$. Then the average risk-free rate implied by (14) is $1.37 \%$, which is comparable to that implied by the power utility model. The Sharpe ratio implied by (17) is 0.40 , which is of the same order of magnitude as the historical Sharpe ratio for excess stock returns. Therefore, the reference-dependent model can simultaneously explain the high equity premium and the low average T-bill rate.

In its most basic implementation, the reference-dependent model fails in an important way, predicting an excessively volatile risk-free rate. The risk-free rate implied by (14) is $-17.02 \%$ when $y_{t}>0$ and $86.71 \%$ when $y_{t}<0$, so the standard deviation of the risk-free rate in the model is an order of magnitude higher than that of the T-bill rate. As discussed above, 
this failure is partly remedied through a habit process that is persistently time varying (i.e., $\phi>0)$. Suppose $\phi=0.68$, which is the structural estimate obtained in the next section. Given this parameter, the standard deviation of the log consumption-habit ratio is $0.74 \%$. For a one-standard-deviation shock around $y_{t}=0$, the risk-free rate is $-2.43 \%$ (40.26\%) when $y_{t}=0.74 \%\left(y_{t}=-0.74 \%\right)$. For a two-standard-deviation shock around $y_{t}=0$, the risk-free rate is $1.17 \%(12.45 \%)$ when $y_{t}=1.47 \%\left(y_{t}=-1.47 \%\right)$. These calculations show that the risk-free rate is less volatile compared to the case with no persistence in the habit process. The next section examines more carefully the extent to which the reference-dependent model is able to explain these asset pricing puzzles.

\section{ESTIMATION OF THE REFERENCE-DEPENDENT MODEL}

This section estimates the asset pricing model based on power reference-dependent utility, whose IMRS is given by equations (10) and (11). Previous empirical tests of habit-based asset pricing models include Ferson and Constantinides (1991), Heaton (1995), Garcia, Re-

nault, and Semenov (2002), and Chen and Ludvigson (2004). Relative to this literature, the preferences in this article have the advantage of explicit behavioral foundations (Köszegi and Rabin 2006), so that the parameters can be interpreted in light of experimental evidence from psychology.

\subsection{Empirical Methodology}

The Euler equation (13) implies the moment restriction

$$
\mathbf{E}\left[\left(M_{t+1} R_{i, t+1}-1\right) z_{t}\right]=0
$$


where $z_{t}$ is a vector of instrumental variables known at time $t$. The reference-dependent model is tested, and its structural parameters are estimated through this moment restriction (Hansen and Singleton 1982). Estimation is by continuous updating generalized method of moments (GMM) (Hansen, Heaton, and Yaron 1996). Newey and Smith (2004) showed that this estimator has desirable higher-order asymptotic properties, implying better performance than two-step GMM (Hansen 1982) in finite samples.

In the benchmark estimates, I fix the parameter $\gamma=1$ (i.e., log utility) for two reasons. First, the model is scale invariant when $\gamma=1$, that is, it does not depend on the units at which consumption is measured. Second, the parameter $\gamma$ has a strong effect on the household's aversion for large gambles, but only a weak effect for small gambles (as discussed in Section 2). Because identification occurs in the domain of small gambles, the parameter is nearly unidentified. (Figure 2 shows that GMM objective function is flat in the direction $\gamma$.) As reported in Table 1, the household's behavior for large-scale risk is perfectly reasonable when $\gamma=1$.

The initial value of the log consumption-habit ratio is set to its unconditional mean, $y_{0}=(\mu-\delta) /(1-\phi)$. The results are not sensitive to reasonable variation in this initial value. All instruments are lagged two quarters to avoid problems with time aggregation in consumption data (Hall 1988).

\subsection{Estimation with Time Series Moments}

\subsubsection{Estimates of Preference Parameters}

In the columns labeled "Moment Set 1" in Table 3, the test assets are the three-month T-bill rate and the excess market return. The instruments are log real consumption growth, log nominal market return, and a constant. (See Appendix C for further details on the data.) These assets and instruments are chosen to capture the low real interest rate, the high equity premium, and the predictability of stock returns. The volatility of the real interest rate, however, is not directly tested by these moment restrictions. The first column reports 
estimates of the unrestricted reference-dependent model, and the second column reports estimates of the model under the parameter restriction $\lambda=1$.

In the unrestricted model, the estimates of the gain-loss utility parameters are $\theta=0.15$ and $\lambda=3.06$. These estimates agree with prior experimental estimates of $\theta=0.12$ and $\lambda=2.25$ (Tversky and Kahneman 1992). The estimate of the subjective discount factor is $\beta=0.88$, which is lower than estimates that are typical for the power utility model. Because loss aversion implies a strong precautionary motive to save, the household must be fairly impatient in order to fit the average T-bill rate. The degree of persistence in the log consumption-habit ratio is $\phi=0.68$. The estimate of $\delta$ is reported as 0.00 , but its actual value is of the order $10^{-6}$. The $J$-test has a $p$-value of $21 \%$, so the model is not rejected at conventional significance levels.

The $J$-test rejects the restricted model with a $p$-value of $3 \%$. Without loss aversion, the only way in which the model can generate volatility in the IMRS, necessary for explaining the high equity premium, is through the parameter $\theta$. To prevent the GMM estimator from converging at arbitrarily large values of $\theta$, I constrain the parameter space to $\theta \leq 0.24$. A large value of $\theta$ is problematic in itself because it is not supported by experimental evidence for diminishing sensitivity.

In the columns labeled "Moment Set 2" in Table 3, the test assets and instruments are the same as moment set 1 , except that the log dividend-price ratio replaces the log market return as an instrument. The dividend-price ratio is chosen to capture the countercyclical variation in the equity premium. The estimates of the preference parameters are essentially the same. The $J$-test has a $p$-value of $9 \%$, so the model is not rejected at the conventional $5 \%$ level.

Figure 1 reports the log consumption-habit ratio and the IMRS, implied by the estimates of the reference-dependent model. The consumption-habit ratio is procyclical, rising in booms and falling in recessions. In deep recessions, consumption falls slightly below habit; the three most recent episodes are 1973-1975, 1980-1982, and 1990-1991. The IMRS has 
mean slightly less than 1, which is required for explaining the low real interest rate. The defining feature of the IMRS is conditional heteroscedasticity. The IMRS is most volatile in recessions when consumption is close to habit. Because the equity premium is proportional to the volatility of the IMRS, the countercyclical volatility of the IMRS leads to a countercylical equity premium.

For moment set 2 , the standard error for $\lambda$ is 5.12 , which is large relative to the point estimate 2.73. This can be explained by an econometric problem known as "weak identification." Because the magnitude of loss aversion is identified from recessions, and recessions are (fortunately) rare events, the parameter is difficult to estimate precisely in finite samples. When there is weak identification, conventional inference based on point estimates and standard errors can be invalid. Fortunately, there are valid econometric methods for constructing confidence intervals that are robust to finite-sample problems. One such method is the $S$-statistic of Stock and Wright (2000). (See Appendix D for a more complete discussion of weak identification.)

Panel (a) of Figure 2 is a plot of the GMM objective function, concentrated in the parameters $\gamma$ and $\lambda$. The height of the concentrated objective function corresponds to the $S$-statistic, which has an asymptotic $\chi^{2}$ distribution under the null. Therefore, the shape of the objective function is useful for inferring economically relevant values of the parameters. For a fixed value of $\gamma$, the objective function is at its highest point when $\lambda=1$, and flattens when $\lambda$ is between 2 and 3. Panel (b) is a contour plot of the objective function reported in Panel (a), which can also be interpreted as the joint confidence interval for the parameters $\gamma$ and $\lambda$. The hypothesis $\lambda<1.8$ is rejected at the $10 \%$ level. In other words, loss aversion is necessary for explaining asset prices. 


\subsubsection{Pricing Errors}

Suppose the T-bill rate is unconditionally riskless, that is, $\operatorname{Cov}\left(M_{t+1}, R_{f, t+1}\right)=0$. Then its return satisfies the trivial equality

$$
\frac{\mathbf{E}\left[M_{t+1} R_{f, t+1}-1\right]}{\mathbf{E}\left[M_{t+1}\right]}=\mathbf{E}\left[R_{f, t+1}\right]-\frac{1}{\mathbf{E}\left[M_{t+1}\right]} .
$$

Since (22) must equal zero in population, its sample analog can be used to assess the magnitude of the pricing error for the T-bill rate. Similarly, any excess return satisfies the trivial equality

$$
\frac{\mathbf{E}\left[M_{t+1} R_{e, t+1}\right]}{\mathbf{E}\left[M_{t+1}\right]}=\mathbf{E}\left[R_{e, t+1}\right]-\operatorname{Cov}\left(\frac{-M_{t+1}}{\mathbf{E}\left[M_{t+1}\right]}, R_{e, t+1}\right) .
$$

Since (23) must equal zero in population, its sample analog can be used to assess the magnitude of the pricing error for the excess market return.

The pricing error for the T-bill rate is $0.43 \%$, and the pricing error for the excess market return is $-0.25 \%$. In other words, the unconditional pricing errors for the referencedependent model are small. This finding is in contrast to previous empirical tests of habitbased asset pricing models, which have found large pricing errors for the unconditional equity premium (see Ferson and Constantinides 1991; Chen and Ludvigson 2004). The intuition for this result is illustrated by the lognormal endowment economy in Section 3. Habit formation is important for explaining the time variation in the equity premium (i.e., fitting conditional moments), but loss aversion is necessary for explaining the high level of the equity premium (i.e., fitting unconditional moments). 


\subsection{Estimation with Cross-Sectional Moments}

\subsubsection{Estimates of Preference Parameters}

In the columns labeled "Moment Set 3" in Table 3, the test assets are the three-month T-bill rate and excess returns on the 25 Fama-French portfolios sorted by size and book-to-market

equity. (See Appendix C for further details on the data.) These assets capture economically important cross-sectional variation in expected stock returns. The parameter estimates are essentially similar to those estimated from the time series moments. One exception is the estimated discount factor, which is somewhat larger at $\beta=0.98$. The $J$-test strongly rejects the model, which indicates that the reference-dependent model is unable to explain the size and value premia.

\subsubsection{Pricing Errors}

Panel A of Table 4 reports the average excess returns for the 25 Fama-French portfolios sorted by size and book-to-market equity. Reading down the columns of the panel, average returns decrease in size for a given book-to-market equity quintile. The only exception is for low book-to-market stocks, whose average returns roughly increase in size. Reading across the rows of the panel, average returns increase in book-to-market equity for a given size quintile.

Panel B reports the pricing errors for each of the Fama-French portfolios, computed through (23). (The pricing error for the T-bill rate is 0.22\%.) Estimation of the referencedependent model is by GMM with the identity weighting matrix, in the spirit of conventional cross-sectional asset pricing tests (e.g., Fama and French 1993). These parameter estimates are not reported because they are close to those reported in Table 3. The pricing errors clearly display a value anomaly; they are negative for growth stocks and positive for value stocks. This is evidence against the reference-dependent model if the value premium is indeed compensation for risk, rather than mispricing. The lesson to be learned from this exercise is 
that the value premium does not appear to be simply compensation for greater volatility in the IMRS during recessions (see Figure 1).

\section{CONCLUSION}

The idea that fluctuations in consumption, rather than wealth, is the relevant measure of risk has a long tradition in economics, rooted in the permanent income hypothesis. The CCAPM has therefore been the canonical economic model of risk and return, despite its many empirical failures. More recent work has shown that habit formation can explain many features of asset prices (e.g., Abel 1999; Campbell and Cochrane 1999). To explain the high equity premium, however, habit-based asset pricing models must ultimately appeal to high risk aversion, which has unappealing implications for large-scale risk.

In contrast, behavioral finance has focused on fluctuations in financial wealth, rather than consumption, as the relevant measure of risk (e.g., Benartzi and Thaler 1995; Barberis, Huang, and Santos 2001). Empirically, consumption and wealth are cointegrated, and the variance of wealth falls to that of consumption in the long run (see Cochrane 1994; Lettau and Ludvigson 2001). Therefore, a measure of risk based on wealth requires that investors care about transitory shocks to wealth above and beyond permanent shocks to consumption. Although the view that investors care about gains and losses in wealth may ultimately be right, it is incompatible with fundamental notions and measures of economic risk. Yet the advantage of the behavioral approach is clear. By using preferences with realistic predictions in the domain of small gambles, behavioral models can explain the equity premium with reasonable levels of large-scale risk aversion.

Relative to this literature, the contribution of this article is to show that the high equity premium can be explained without appealing to high risk aversion or having preferences over wealth. By doing so, this article introduces an alternative view that investors perceive even small fluctuations in consumption as risky, even though large-scale risk aversion is 
low. Essentially, the model developed in this article relies on consumption as the relevant measure of risk, but uses behaviorally realistic preferences. Investors are averse to losses in consumption relative to time-varying habit, and the fear of losses generates the high level and countercyclical variation of the equity premium.

\section{ACKNOWLEDGMENTS}

I have benefited from comments by Andrew Abel, John Campbell, René Garcia, Eric Renault, Robert Stambaugh, Adam Szeidl, Jessica Wachter, Lu Zhang (discussant), the referees, an associate editor, and seminar participants at Université de Montréal, Wharton, and the 2005 Conference on Simulation Based and Finite Sample Inference in Finance. 


\section{Appendix A EXPONENTIAL GAIN-LOSS UTILITY}

The exponential gain-loss function (Köbberling and Wakker 2005) is specified as

$$
W_{E}(z)=\left\{\begin{array}{ll}
\frac{1-\exp \{-\theta z\}}{\theta} & \text { for } z \geq 0 \\
\lambda \frac{\exp \{\theta z\}-1}{\theta} & \text { for } z<0
\end{array} \quad(\theta \geq 0, \lambda>1) .\right.
$$

The parameter $\theta$ determines the degree of diminishing sensitivity, and the parameter $\lambda$ determines the degree of loss aversion. When $\theta>0$, the exponential gain-loss function satisfies the strong version of diminishing sensitivity (Property $2^{\prime}$ ). The special case $\theta=0$ is understood to be the linear gain-loss function (4).

Exponential reference-dependent utility is defined as a special case of reference-dependent utility with power consumption utility (2) and exponential gain-loss utility (24). The marginal utility of consumption in this case is

$$
u_{C}=\left\{\begin{array}{ll}
C^{-\gamma} \exp \left\{-\theta\left(\frac{C^{1-\gamma}}{1-\gamma}-\frac{X^{1-\gamma}}{1-\gamma}\right)\right\} & \text { for } C>X \\
\lambda C^{-\gamma} \exp \left\{\theta\left(\frac{C^{1-\gamma}}{1-\gamma}-\frac{X^{1-\gamma}}{1-\gamma}\right)\right\} & \text { for } C<X
\end{array} .\right.
$$

When consumption is close to its reference level, marginal utility can be approximated as

$$
u_{C} \approx\left\{\begin{array}{cc}
C^{-\gamma} & \text { for } C>X \\
\lambda C^{-\gamma} & \text { for } C<X
\end{array} .\right.
$$

In this approximation, the marginal utility of consumption is the same as that of standard power utility when $C>X$. When $C<X$, however, marginal utility is higher than that of power utility due to loss aversion. The higher is the degree of loss aversion, the higher is marginal utility when consumption is below its reference level.

To motivate exponential reference-dependent utility, consider the special case when consumption utility takes the log utility form (i.e., $\gamma=1$ ). Household utility simplifies to yield 
the ratio specification

$$
u(C, X)=\left\{\begin{array}{ll}
\frac{1-(C / X)^{-\theta}}{\theta} & \text { for } C \geq X \\
\lambda \frac{(C / X)^{\theta}-1}{\theta} & \text { for } C<X
\end{array} .\right.
$$

This specification has appeared in applications by Garcia, Renault, and Semenov (2002) and Kyle, Ou-Yang, and Xiong (2006).

\section{Appendix B PROOFS OF PROPOSITIONS}

\section{B.1 Proof of Proposition 1}

The proof is essentially an application of the following lemma.

Lemma 1. If $g \sim \mathbf{N}\left(\mu, \sigma^{2}\right)$,

$$
\begin{aligned}
& \mathbf{E}\left[e^{g} \mid g>\bar{x}\right]=\exp \left\{\mu+\frac{\sigma^{2}}{2}\right\} \frac{F\left(-\left(\bar{x}-\mu-\sigma^{2}\right) / \sigma\right)}{F(-(\bar{x}-\mu) / \sigma)} \\
& \mathbf{E}\left[e^{g} \mid g<\bar{x}\right]=\exp \left\{\mu+\frac{\sigma^{2}}{2}\right\} \frac{F\left(\left(\bar{x}-\mu-\sigma^{2}\right) / \sigma\right)}{F((\bar{x}-\mu) / \sigma)}
\end{aligned}
$$

where $F(\cdot)$ is the cumulative distribution function of the standard normal.

Let $\bar{x}_{t+1}=x_{t+1}-c_{t}=\delta-\phi y_{t}$. The IMRS can be written as

$$
M_{t+1}=\left\{\begin{array}{cl}
\frac{\beta \exp \left\{-\gamma g_{t+1}\right\}}{w_{L}\left(y_{t}\right)} & \text { for } g_{t+1}>\bar{x}_{t+1} \\
\frac{\lambda \beta \exp \left\{-\gamma g_{t+1}\right\}}{w_{L}\left(y_{t}\right)} & \text { for } g_{t+1}<\bar{x}_{t+1}
\end{array}\right.
$$

where

$$
w_{L}\left(y_{t}\right)=\left\{\begin{array}{ll}
1 & \text { for } y_{t}>0 \\
\lambda & \text { for } y_{t}<0
\end{array} .\right.
$$


For any $n>0$,

$$
\begin{aligned}
\mathbf{E}_{t}\left[M_{t+1}^{n}\right]= & \left(\frac{\beta}{w_{L}\left(y_{t}\right)}\right)^{n}\left\{F\left(-\frac{\bar{x}_{t+1}-\mu}{\sigma}\right) \mathbf{E}_{t}\left[e^{-n \gamma g_{t+1}} \mid g_{t+1}>\bar{x}_{t+1}\right]\right. \\
& \left.+\lambda^{n} F\left(\frac{\bar{x}_{t+1}-\mu}{\sigma}\right) \mathbf{E}_{t}\left[e^{-n \gamma g_{t+1}} \mid g_{t+1}<\bar{x}_{t+1}\right]\right\}
\end{aligned}
$$

By Lemma 1,

$$
\begin{aligned}
& \mathbf{E}_{t}\left[e^{-n \gamma g_{t+1}} \mid g_{t+1}>\bar{x}_{t+1}\right]=\exp \left\{-n \gamma \mu+\frac{(n \gamma \sigma)^{2}}{2}\right\} \frac{\left.F\left(-n \gamma \sigma-\left(\bar{x}_{t+1}-\mu\right) / \sigma\right)\right)}{F\left(-\left(\bar{x}_{t+1}-\mu\right) / \sigma\right)} \\
& \mathbf{E}_{t}\left[e^{-n \gamma g_{t+1}} \mid g_{t+1}<\bar{x}_{t+1}\right]=\exp \left\{-n \gamma \mu+\frac{(n \gamma \sigma)^{2}}{2}\right\} \frac{F\left(n \gamma \sigma+\left(\bar{x}_{t+1}-\mu\right) / \sigma\right)}{F\left(\left(\bar{x}_{t+1}-\mu\right) / \sigma\right)}
\end{aligned}
$$

Therefore,

$$
\mathbf{E}_{t}\left[M_{t+1}^{n}\right]=\left(\frac{\beta}{w_{L}\left(y_{t}\right)}\right)^{n} \exp \left\{-n \gamma \mu+\frac{(n \gamma \sigma)^{2}}{2}\right\}\left[1+\left(\lambda^{n}-1\right) F\left(n \gamma \sigma+\frac{\bar{x}_{t+1}-\mu}{\sigma}\right)\right]
$$

For a conditionally risk-free asset, the Euler equation (13) can be written as

$$
R_{f, t+1}=\mathbf{E}_{t}\left[M_{t+1}\right]^{-1}
$$

This equation, together with (28) for $n=1$, implies (14).

\section{B.2 Proof of Proposition 2}

The Euler equation for an excess return is $\mathbf{E}_{t}\left[M_{t+1} R_{e, t+1}\right]=0$. As shown by Shiller (1982) and Hansen and Jagannathan (1991),

$$
\frac{\mathbf{E}_{t}\left[R_{e, t+1}\right]}{\sigma_{t}\left(R_{e, t+1}\right)} \leq \frac{\sigma_{t}\left(M_{t+1}\right)}{\mathbf{E}_{t}\left[M_{t+1}\right]}=\left(\frac{\mathbf{E}_{t}\left[M_{t+1}^{2}\right]}{\mathbf{E}_{t}\left[M_{t+1}\right]^{2}}-1\right)^{1 / 2}
$$

This equation, together with (28) for $n=1,2$, implies (17). 
By differentiation of (18),

$$
\frac{\partial B_{t}(\gamma, \lambda)}{\partial \lambda}=\frac{2 C_{t}(\gamma, \lambda)}{\left[1+(\lambda-1) F\left(\gamma \sigma+\left(\delta-\mu-\phi y_{t}\right) / \sigma\right)\right]^{3}}
$$

where

$$
\begin{aligned}
C_{t}(\gamma, \lambda)= & \lambda F\left(2 \gamma \sigma+\frac{\delta-\mu-\phi y_{t}}{\sigma}\right)\left[1-F\left(\gamma \sigma+\frac{\delta-\mu-\phi y_{t}}{\sigma}\right)\right] \\
& -F\left(\gamma \sigma+\frac{\delta-\mu-\phi y_{t}}{\sigma}\right)\left[1-F\left(2 \gamma \sigma+\frac{\delta-\mu-\phi y_{t}}{\sigma}\right)\right] .
\end{aligned}
$$

If $C_{t}(\gamma, \lambda)>0, \partial B_{t}(\gamma, \lambda) / \partial \lambda>0$. Property 1 therefore follows from the fact that

$$
C_{t}(\gamma, \lambda)>(\lambda-1) F\left(\gamma \sigma+\frac{\delta-\mu-\phi y_{t}}{\sigma}\right)\left[1-F\left(\gamma \sigma+\frac{\delta-\mu-\phi y_{t}}{\sigma}\right)\right]>0
$$

By differentiation of (18),

$$
\frac{\partial B_{t}(\gamma, \lambda)}{\partial y_{t}}=-\frac{\phi(\lambda-1) D_{t}(\gamma, \lambda)}{\sigma\left[1+(\lambda-1) F\left(\gamma \sigma+\left(\delta-\mu-\phi y_{t}\right) / \sigma\right)\right]^{3}},
$$

where

$$
\begin{aligned}
D_{t}(\gamma, \lambda)= & F^{\prime}\left(2 \gamma \sigma+\frac{\delta-\mu-\phi y_{t}}{\sigma}\right)\left[1+\lambda+\left(\lambda^{2}-1\right) F\left(\gamma \sigma+\frac{\delta-\mu-\phi y_{t}}{\sigma}\right)\right] \\
& -2 F^{\prime}\left(\gamma \sigma+\frac{\delta-\mu-\phi y_{t}}{\sigma}\right)\left[1+\left(\lambda^{2}-1\right) F\left(2 \gamma \sigma+\frac{\delta-\mu-\phi y_{t}}{\sigma}\right)\right] .
\end{aligned}
$$

If $D_{t}(0, \lambda)>0, \partial B_{t}(0, \lambda) / \partial y_{t}<0$. Property 2 therefore follows from the fact that

$$
D_{t}(0, \lambda)=(\lambda-1) F^{\prime}\left(\frac{\delta-\mu-\phi y_{t}}{\sigma}\right)\left[1-(\lambda+1) F\left(\frac{\delta-\mu-\phi y_{t}}{\sigma}\right)\right]>0
$$

if inequality (19) holds. 


\section{Appendix C CONSUMPTION AND ASSET RETURNS DATA}

\section{C.1 Consumption}

Quarterly consumption data for the sample period 1947-2004 is from the U.S. national accounts. Following convention, consumption is measured as the (chain-weighted) sum of real personal consumption expenditures (PCE) on nondurable goods and services, divided by the population. In matching consumption to returns data, I use "beginning of the period" timing convention, following Campbell (2003). In other words, the reported consumption for each period $t$ is assumed to be the flow on the first (rather than the last) day of period $t$.

\section{C.2 Asset Returns}

The three Fama-French factors are excess returns on the market portfolio, returns on the SMB portfolio, and returns on the HML portfolio. The excess market return is the return on a value-weighted portfolio of NYSE, AMEX, and Nasdaq stocks minus the one-month T-bill rate. The SMB and HML portfolios are based on the six Fama-French benchmark portfolios sorted by size (breakpoint at the median) and book-to-market equity (breakpoints at the 30th and 70th percentiles). The SMB return is the difference in average returns between three small and three big stock portfolios. The HML return is the difference in average returns between two high and two low book-to-market portfolios.

The 25 Fama-French portfolios are constructed from an independent sort of all NYSE, AMEX, and Nasdaq stocks into quintiles based on size (i.e., market equity) and book-tomarket equity. Data on the Fama-French factors and portfolios are obtained from Kenneth French's webpage. See Fama and French (1993) for further details on the construction of the factors and portfolios.

The three-month T-bill rate is from the Center for Research in Security Prices (CRSP) 
Indices database. The three-month T-bill is used as the empirical proxy for the risk-rate, except in constructing the excess market return as discussed previously. All nominal returns are deflated by the price index for PCE on nondurable goods and services.

The dividend-price ratio is constructed as the dividend over the past year divided by the current price for the CRSP value-weighted portfolio. The dividend-price ratio is related, by a present-value relationship, to the expectation of future returns and dividend growth and therefore predicts returns (Campbell and Shiller 1988).

\section{Appendix D GMM TEST ROBUST TO WEAK IDEN- TIFICATION}

Let $\theta$ be an $N$-dimensional parameter vector in the interior of a compact parameter space $\Theta$. The true parameter $\theta_{0}$ is assumed to satisfy $M$ conditional moment restrictions

$$
\mathbf{E}_{t-1}\left[h\left(y_{t}, \theta_{0}\right)\right]=0
$$

Let $z_{t-1}$ be a vector of $I$ instrumental variables known at $t-1$, and define the moment function

$$
g_{t}(\theta)=h\left(y_{t}, \theta\right) \otimes z_{t-1}
$$

The continuous updating GMM estimator minimizes the objective function

$$
S(\theta)=T g(\theta)^{\prime} \Omega(\theta)^{-1} g(\theta)
$$


where

$$
\begin{aligned}
g(\theta) & =\frac{1}{T} \sum_{t=1}^{T} g_{t}(\theta), \\
\Omega(\theta) & =\frac{1}{T} \sum_{t=1}^{T} g_{t}(\theta) g_{t}(\theta)^{\prime} .
\end{aligned}
$$

Weak identification occurs when the population objective function $\mathbf{E}\left[g_{t}(\theta)\right]$ is close to zero for a large set of $\theta \neq \theta_{0}$. When $g_{t}(\theta)$ is linear in $\theta$ (i.e., linear instrumental variables regression model), weak identification is more commonly referred to as "weak instruments." When there is weak identification, conventional GMM tests may be invalid, that is, reject the null hypothesis too frequently, even in large samples. For a survey of weak identification in GMM, see Stock, Wright, and Yogo (2002). For its empirical relevance in estimating asset pricing moment restrictions, see Stock and Wright (2000), Neely, Roy, and Whiteman (2001), and Yogo (2004).

Following Stock and Wright (2000), partition the parameter vector as $\theta=\left(\theta_{W}^{\prime}, \theta_{S}^{\prime}\right)^{\prime}$. $\theta_{W}$ is an $N_{W}$-dimensional subvector of weakly identified parameters, and $\theta_{S}$ is an $N_{S}$-dimensional subvector of strongly identified parameters. Therefore, $\theta_{W}$ denotes the dimensions of $\theta$ for which the population objective function is close to zero for a large set of $\theta_{W} \neq \theta_{W 0}$.

Stock and Wright (2000) proposed a test for $\theta_{W}$, based on the continuous updating GMM objective function, that is valid even when there is weak identification. For a given $\theta_{W}$, let

$$
\widehat{\theta}_{S}\left(\theta_{W}\right)=\arg \min _{\theta_{S} \in \Theta_{S}} S(\theta)
$$

be the estimate of $\theta_{S}$ that minimizes the objective function. Let $\widehat{\theta}_{W}=\left(\theta_{W}^{\prime}, \widehat{\theta}_{S}\left(\theta_{W}\right)^{\prime}\right)^{\prime}$. Under the null $\theta_{W}=\theta_{W 0}$, the statistic $S\left(\widehat{\theta}_{W}\right)$ has the asymptotic distribution $\chi_{M I-N_{S}}^{2}$ (Stock and Wright 2000, thm. 3). 



\section{References}

Abel, A. B. (1990), "Asset Prices under Habit Formation and Catching Up with the Joneses," American Economic Review, 80, 38-42.

— (1999), "Risk Premia and Term Premia in General Equilibrium," Journal of Monetary Economics, 43, 3-33.

Barberis, N. and Huang, M. (2007), "The Loss Aversion/Narrow Framing Approach to the Equity Premium Puzzle," in Handbook of Investments: Equity Risk Premium, ed. Mehra, R., Amsterdam: Elsevier, vol. 1, chap. 5, p. forthcoming.

Barberis, N., Huang, M., and Santos, T. (2001), "Prospect Theory and Asset Prices," Quarterly Journal of Economics, 116, 1-53.

Bekaert, G., Hodrick, R. J., and Marshall, D. A. (1997), "The Implications of First-Order Risk Aversion for Asset Market Risk Premiums," Journal of Monetary Economics, 40, 3-39.

Benartzi, S. and Thaler, R. H. (1995), "Myopic Loss Aversion and the Equity Premium Puzzle," Quarterly Journal of Economics, 110, 73-92.

Bonomo, M. and Garcia, R. (1994), "Disappointment Aversion as a Solution to the Equity Premium and the Risk-Free Rate Puzzles," Unpublished manuscript, Université de Montréal.

Bowman, D., Minehart, D., and Rabin, M. (1999), "Loss Aversion in a Consumption-Savings Model," Journal of Economic Behavior and Organization, 38, 155-178.

Campbell, J. Y. (2003), "Consumption-Based Asset Pricing," in Handbook of the Economics of Finance, eds. Constantinides, G. M., Harris, M., and Stulz, R. M., Amsterdam: Elsevier, vol. 1B, chap. 13, pp. 801-885. 
Campbell, J. Y. and Cochrane, J. H. (1999), "By Force of Habit: A Consumption-Based Explanation of Aggregate Stock Market Behavior," Journal of Political Economy, 107, 205-251.

Campbell, J. Y. and Shiller, R. J. (1988), "The Dividend-Price Ratio and Expectations of Future Dividends and Discount Factors," Review of Financial Studies, 1, 195-228.

Chen, X. and Ludvigson, S. C. (2004), "Land of Addicts? An Empirical Investigation of Habit-Based Asset Pricing Models," Unpublished manuscript, New York University.

Cochrane, J. H. (1994), "Permanent and Transitory Components of GNP and Stock Prices," Quarterly Journal of Economics, 109, 241-265.

Constantinides, G. M. (1990), "Habit Formation: A Resolution of the Equity Premium Puzzle," Journal of Political Economy, 98, 519-543.

Epstein, L. G. and Zin, S. E. (1990), "'First-Order' Risk Aversion and the Equity Premium Puzzle," Journal of Monetary Economics, 26, 387-407.

- (2001), "The Independence Axiom and Asset Returns," Journal of Empirical Finance, 8, $537-72$.

Fama, E. F. and French, K. R. (1993), "Common Risk Factors in the Returns on Stocks and Bonds," Journal of Financial Economics, 33, 3-56.

Ferson, W. E. and Constantinides, G. M. (1991), "Habit Persistence and Durability in Aggregate Consumption: Empirical Tests," Journal of Financial Economics, 29, 199-240.

Frederick, S. and Loewenstein, G. (1999), "Hedonic Adaptation," in Well-Being: Foundations of Hedonic Psychology, eds. Kahneman, D., Diener, E., and Schwartz, N., New York: Russell Sage Foundation, chap. 16, pp. 302-329.

Garcia, R., Renault, E., and Semenov, A. (2002), "A Consumption CAPM with a Reference Level," Unpublished manuscript, Université de Montréal. 
Grossman, S. J. and Shiller, R. J. (1981), "The Determinants of the Variability of Stock Market Prices," American Economic Review, 71, 222-227.

Gul, F. (1991), "A Theory of Disappointment Aversion,” Econometrica, 59, 667-686.

Hall, R. E. (1988), "Intertemporal Substitution in Consumption," Journal of Political Economy, 96, 339-357.

Hansen, L. P. (1982), "Large Sample Properties of Generalized Method of Moments Estimators," Econometrica, 50, 1029-1054.

Hansen, L. P., Heaton, J., and Yaron, A. (1996), "Finite-Sample Properties of Some Alternative GMM Estimators," Journal of Business and Economic Statistics, 14, 262-280.

Hansen, L. P. and Jagannathan, R. (1991), "Implications of Security Market Data for Models of Dynamic Economies," Journal of Political Economy, 99, 225-262.

Hansen, L. P. and Singleton, K. J. (1982), "Generalized Instrumental Variables Estimation of Nonlinear Rational Expectations Models," Econometrica, 50, 1269-1286.

Heaton, J. (1995), "An Empirical Investigation of Asset Pricing with Temporally Dependent Preference Specifications," Econometrica, 63, 681-717.

Kahneman, D. and Tversky, A. (1979), "Prospect Theory: An Analysis of Decision under Risk," Econometrica, 47, 263-291.

Kandel, S. and Stambaugh, R. F. (1990), "Expectations and Volatility of Consumption and Asset Returns," Review of Financial Studies, 3, 207-232.

— (1991), "Asset Returns and Intertemporal Preferences," Journal of Monetary Economics, $27,39-71$.

Kőszegi, B. and Rabin, M. (2006), "A Model of Reference-Dependent Preferences," Quarterly Journal of Economics, 121, 1133-1165. 
Köbberling, V. and Wakker, P. P. (2005), "An Index of Loss Aversion," Journal of Economic Theory, 122, 119-131.

Kyle, A. S., Ou-Yang, H., and Xiong, W. (2006), "Prospect Theory and Liquidation Decisions," Journal of Economic Theory, 129, 273-288.

Lettau, M. and Ludvigson, S. (2001), "Consumption, Aggregate Wealth, and Expected Stock Returns," Journal of Finance, 56, 815-849.

Mehra, R. and Prescott, E. C. (1985), "The Equity Premium: A Puzzle," Journal of Monetary Economics, 15, 145-161.

Neely, C. J., Roy, A., and Whiteman, C. H. (2001), "Risk Aversion Versus Intertemporal Substitution: A Case Study of Identification Failure in the Intertemporal Consumption Capital Asset Pricing Model," Journal of Business and Economic Statistics, 19, 395-403.

Newey, W. K. and Smith, R. J. (2004), "Higher Order Properties of GMM and Generalized Empirical Likelihood Estimators," Econometrica, 72, 219-255.

Parker, J. A. (2001), "The Consumption Risk of the Stock Market," Brookings Papers on Economic Activity, 2, 279-333.

Rabin, M. (2000), "Risk Aversion and Expected-utility Theory: A Calibration Theorem," Econometrica, 68, 1281-1292.

Segal, U. and Spivak, A. (1990), "First Order versus Second Order Risk Aversion," Journal of Economic Theory, 51, 111-125.

Shiller, R. J. (1982), "Consumption, Asset Markets and Macroeconomic Fluctuations," Carnegie-Rochester Conference Series on Public Policy, 17, 203-238.

Stock, J. H. and Wright, J. H. (2000), "GMM with Weak Identification," Econometrica, 68, 1055-1096. 
Stock, J. H., Wright, J. H., and Yogo, M. (2002), "A Survey of Weak Instruments and Weak Identification in Generalized Method of Moments," Journal of Business and Economic Statistics, 20, 518-529.

Sundaresan, S. M. (1989), "Intertemporally Dependent Preferences and the Volatility of Consumption and Wealth," Review of Financial Studies, 2, 73-89.

Tversky, A. and Kahneman, D. (1992), "Advances in Prospect Theory: Cumulative Representation of Uncertainty," Journal of Risk and Uncertainty, 5, 297-323.

Weil, P. (1989), "The Equity Premium Puzzle and the Risk-Free Rate Puzzle," Journal of Monetary Economics, 24, 401-421.

Yogo, M. (2004), "Estimating the Elasticity of Intertemporal Substitution When Instruments Are Weak," Review of Economics and Statistics, 86, 797-810. 
Table 1: Certainty equivalent of small and large gambles under reference-dependent utility

\begin{tabular}{crrr}
\hline \hline & & \multicolumn{2}{c}{ Reference-Dependent Utility } \\
\cline { 3 - 4 }$\gamma$ & Power Utility & $\theta=0$ & $\theta=0.12$ \\
\hline \multicolumn{2}{c}{ Panel A: Small Gambles $( \pm \$ 375)$} & \\
0.0 & 0.00 & 104.17 & 87.48 \\
0.5 & 0.47 & 104.47 & 87.74 \\
1.0 & 0.94 & 104.78 & 87.99 \\
2.0 & 1.88 & 105.38 & 88.51 \\
5.0 & 4.69 & 107.19 & 90.06 \\
10.0 & 9.38 & 110.18 & 92.65 \\
30.0 & 28.03 & 121.91 & 102.92 \\
Panel B: Large Gambles $( \pm \$ 25,000)$ & \\
0.0 & 0 & 6,944 & 5,831 \\
0.5 & 2,145 & 8,359 & 7,066 \\
1.0 & 4,289 & 9,720 & 8,301 \\
2.0 & 8,333 & 12,209 & 10,685 \\
5.0 & 16,434 & 17,424 & 16,244 \\
10.0 & 21,009 & 21,088 & 20,501 \\
30.0 & 23,791 & 23,791 & 23,623 \\
\hline
\end{tabular}

NOTE: Panel A (Panel B) reports the sure loss in wealth that equates utility to a gamble of $\pm \$ 375( \pm \$ 25,000)$ with equal probability. The household's initial wealth and its reference level of consumption are $\$ 75,000$. The table reports outcomes for power reference-dependent utility at varying degrees of diminishing sensitivity $(\theta)$ and risk aversion $(\gamma)$. The degree of loss aversion is fixed at $\lambda=2.25$. 
Table 2: Descriptive statistics for consumption and asset returns

\begin{tabular}{lrrr}
\hline \hline Variable & Mean (\%) & S.D. (\%) & Sharpe Ratio \\
\hline Consumption Growth & 0.50 & 0.54 & \\
T-bill Rate & 0.36 & 0.75 & \\
Market Return & 1.99 & 8.04 & 0.25 \\
SMB Return & 0.61 & 5.42 & 0.11 \\
HML Return & 1.04 & 5.63 & 0.19 \\
\hline
\end{tabular}

NOTE: The table reports the mean and standard deviation of consumption growth, threemonth T-bill rate, excess market return, SMB return, and HML return. The Sharpe ratio is the mean excess return divided by its standard deviation. All returns are deflated by the price index for consumption and are reported in percent per quarter. The sample period is quarterly 1947-2004. 
Table 3: Parameters of the reference-dependent model

\begin{tabular}{crrrrrr}
\hline \hline & \multicolumn{2}{c}{ Moment Set 1 } & \multicolumn{3}{c}{ Moment Set 2 } & \multicolumn{2}{c}{ Moment Set 3 } \\
\cline { 2 - 7 } Parametery & Unrestricted & $\lambda=1$ & Unrestricted & $\lambda=1$ & Unrestricted & $\lambda=1$ \\
\hline$\beta$ & 0.88 & 0.94 & 0.87 & 0.96 & 0.98 & 1.00 \\
& $(0.05)$ & $(0.05)$ & $(0.06)$ & $(0.06)$ & $(0.05)$ & $(0.02)$ \\
$\theta$ & 0.15 & 0.24 & 0.13 & 0.24 & 0.16 & 0.16 \\
& $(0.47)$ & $(0.48)$ & $(0.56)$ & $(0.64)$ & $(0.30)$ & $(0.36)$ \\
$\lambda$ & 3.06 & & 2.73 & & 3.43 & \\
& $(3.12)$ & & $(5.12)$ & & $(1.63)$ & \\
$\delta$ & 0.00 & 0.00 & 0.00 & 0.00 & 0.00 & 0.00 \\
& $(0.00)$ & $(0.00)$ & $(0.00)$ & $(0.00)$ & $(0.00)$ & $(0.00)$ \\
$\phi$ & 0.68 & 0.68 & 0.69 & 0.68 & 0.69 & 0.78 \\
& $(0.14)$ & $(0.07)$ & $(0.00)$ & $(0.47)$ & $(0.00)$ & $(0.24)$ \\
$J$-test & 1.54 & 4.66 & 2.86 & 11.40 & 73.90 & 74.84 \\
& $(0.21)$ & $(0.03)$ & $(0.09)$ & $(0.00)$ & $(0.00)$ & $(0.00)$ \\
\hline
\end{tabular}

NOTE: In moment set 1, the test assets are the three-month T-bill rate and the excess market return. The instruments are log real consumption growth, log nominal market return, and a constant. Moment set 2 is the same as moment set 1, except that the log dividend-price ratio replaces the log market return as an instrument. In moment set 3, the test assets are the three-month T-bill rate and excess returns on the 25 Fama-French portfolios. For each set of moments, the table reports estimates of the unrestricted and restricted (i.e., $\lambda=1$ ) reference-dependent model. Estimation is by continuous updating GMM. Standard errors and $p$-values for the $J$-test (i.e., test of overidentifying restrictions) in parentheses. 
Table 4: Pricing errors for the Fama-French portfolios

\begin{tabular}{|c|c|c|c|c|c|}
\hline \multirow[b]{2}{*}{ Size } & \multicolumn{5}{|c|}{ Book-to-Market Equity } \\
\hline & Low & 2 & 3 & 4 & High \\
\hline \multicolumn{6}{|c|}{ Panel A: Average Excess Return (\%) } \\
\hline Small & 1.16 & 2.55 & 2.65 & 3.25 & 3.74 \\
\hline 2 & 1.46 & 2.33 & 2.84 & 2.97 & 3.47 \\
\hline 3 & 1.75 & 2.38 & 2.41 & 2.83 & 3.17 \\
\hline 4 & 1.93 & 1.91 & 2.65 & 2.60 & 2.94 \\
\hline Big & 1.72 & 1.74 & 2.07 & 2.05 & 2.21 \\
\hline \multicolumn{6}{|c|}{ Panel B: Pricing Errors (\%) } \\
\hline Small & -2.17 & -0.36 & 0.05 & 0.70 & 1.03 \\
\hline 2 & -1.59 & -0.38 & 0.29 & 0.72 & 0.96 \\
\hline 3 & -0.98 & 0.07 & 0.12 & 0.62 & 0.86 \\
\hline 4 & -0.31 & -0.18 & 0.57 & 0.45 & 0.73 \\
\hline Big & -0.16 & -0.03 & 0.93 & 0.27 & 0.50 \\
\hline
\end{tabular}

NOTE: Panel A reports average excess returns (percent per quarter) on the 25 Fama-French portfolios sorted by size and book-to-market equity. Panel B reports pricing errors from estimation of the reference-dependent model. The test assets are the three-month T-bill rate and excess returns on the Fama-French portfolios. Estimation is by GMM with the identity weighting matrix. 


\section{(a) Consumption in Excess of Habit}

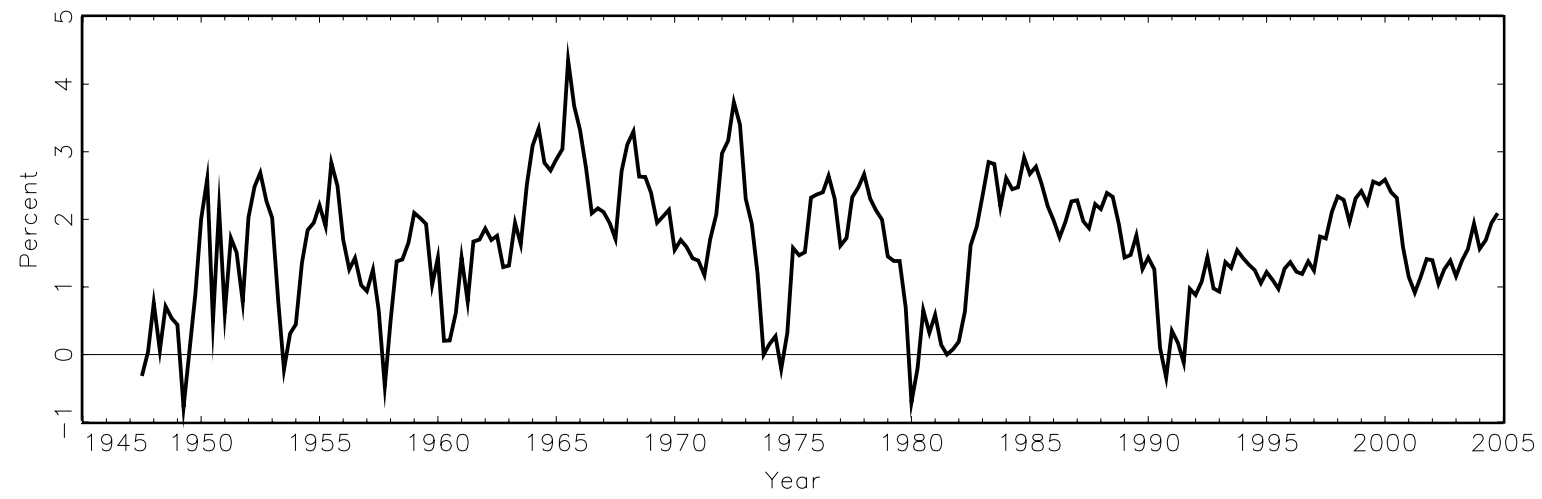

(b) IMRS

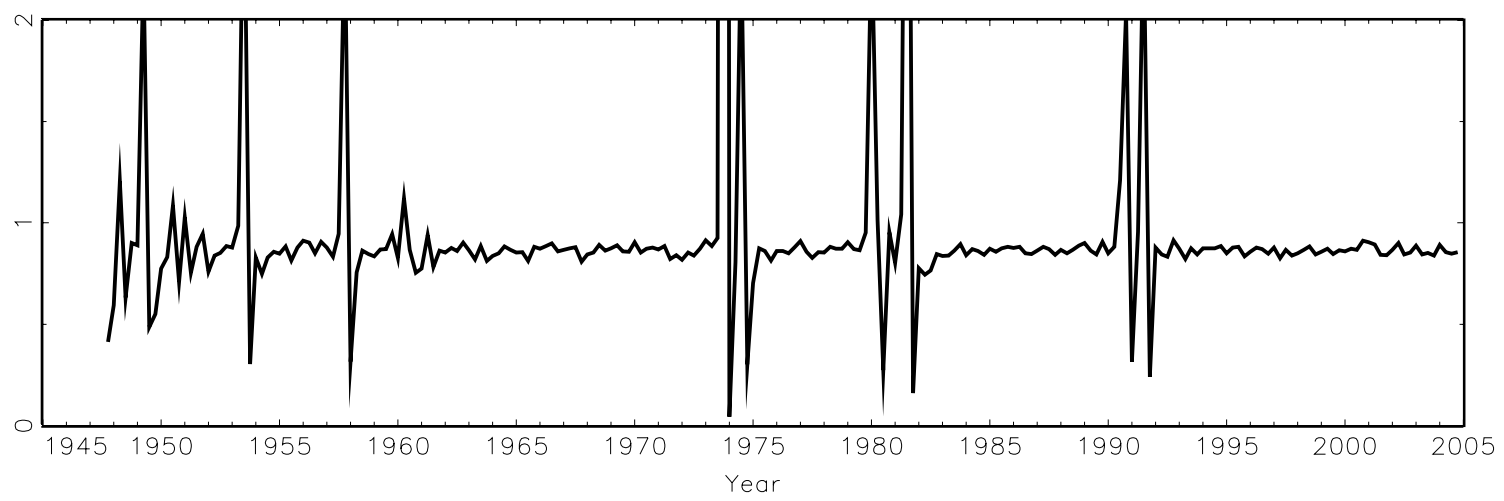

Figure 1: Consumption-habit ratio and the IMRS. Panel (a) is a plot of the log consumptionhabit ratio. Panel (b) is a plot of the IMRS implied by estimates of the reference-dependent model using moment set 2 , reported in Table 3 . 
(a) Concentrated GMM Objective Function

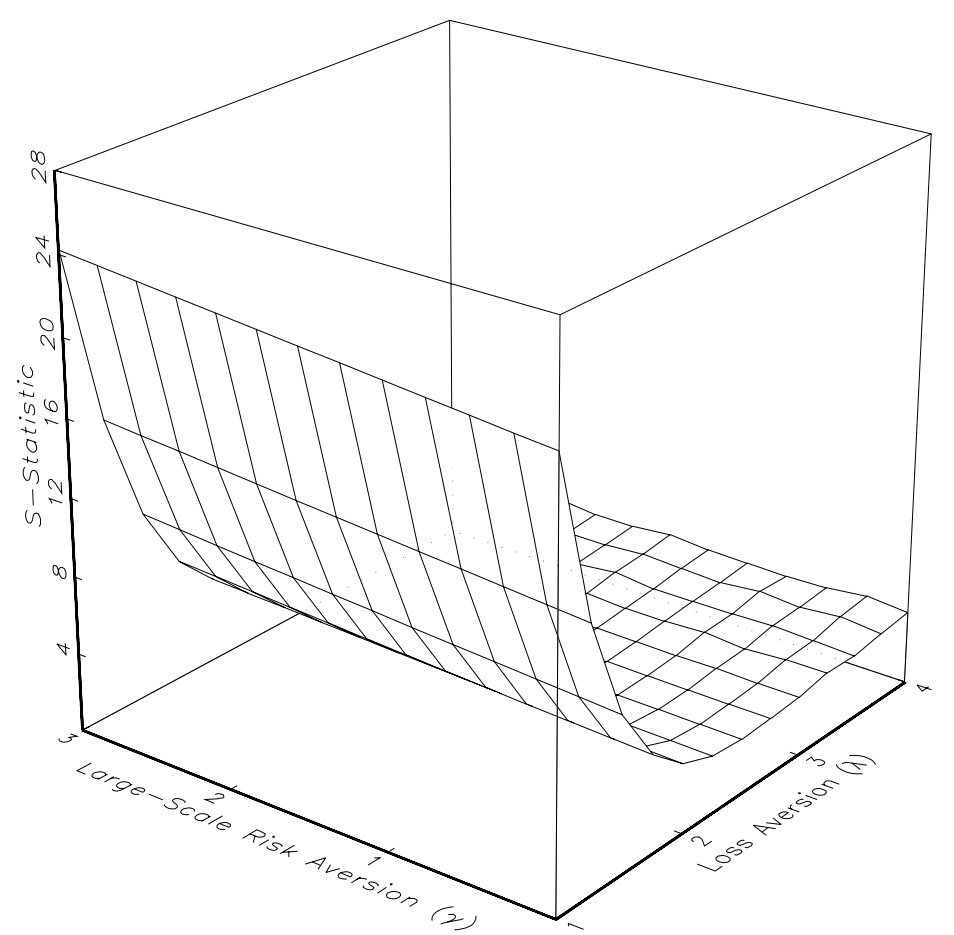

(b) Joint Confidence Interval for Preference Parameters

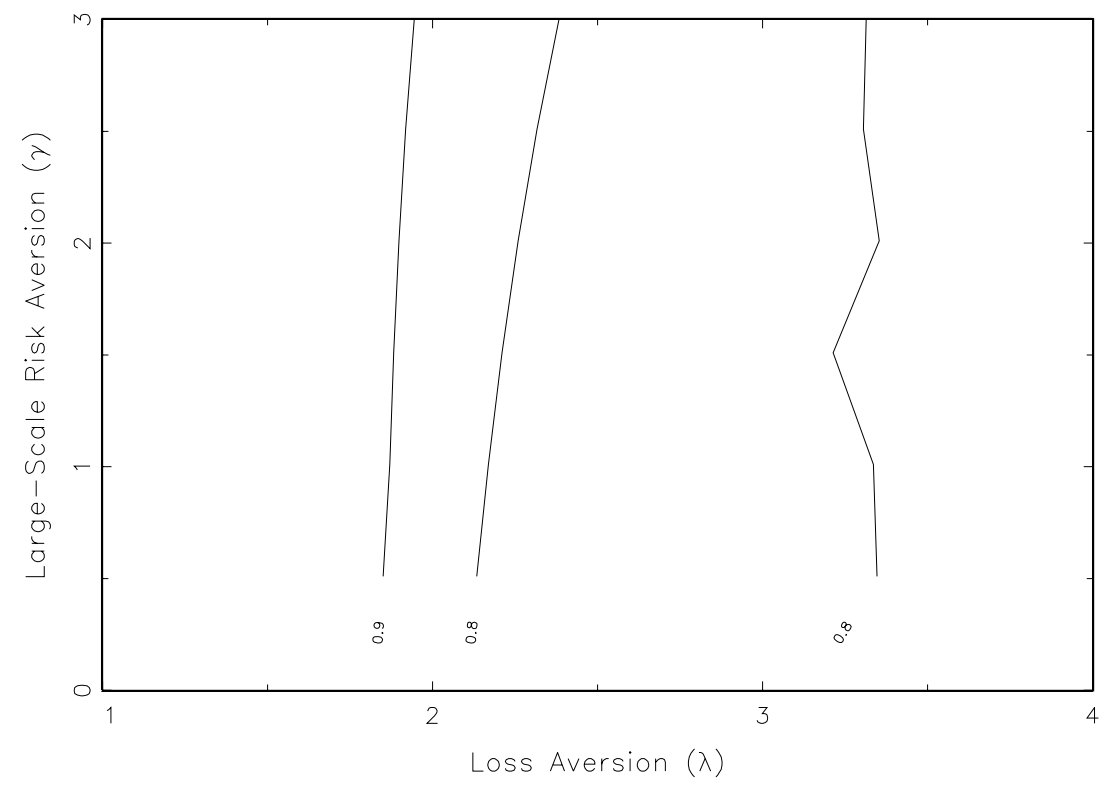

Figure 2: GMM objective function for the reference-dependent model. Panel (a) is a plot of the GMM objective function for the reference-dependent model, concentrated in the parameters $\gamma$ and $\lambda$. Panel (b) is a contour plot of the objective function reported in Panel (a). The contours are labeled as 1 minus the $p$-value of the corresponding GMM objective function test. 
Members of the Center

2006-2007

Directing Members

Aronson + Johnson + Ortiz, LP

Geewax, Terker \& Company

Brandywine Global Investment Management, LLC

Goldman, Sachs \& Co.

Hirtle, Callaghan \& Company

Merrill Lynch

Morgan Stanley

The NASDAQ Stock Market Educational Foundation

The New York Stock Exchange, Inc.

Founding Members

Ford Motor Company Fund

Merrill Lynch, Pierce, Fenner \& Smith, Inc.

Oppenheimer \& Company

Philadelphia National Bank

Salomon Brothers

Weiss, Peck and Greer 